\title{
sciendo
}

\subsection{8/genst-2021-0007}

\section{DOES TRADITIONAL MEAN GOOD? \\ A PILOT STUDY ON UNIVERSITY STUDENTS' PERCEPTIONS OF DIFFERENT TYPES OF WOMEN AND MEN}

\author{
KRISTINA FERNANDES \\ University of Vienna, Austria \\ kristina.dziallas@univie.ac.at
}

\begin{abstract}
Gender stereotyping remains a pervasive issue in society. Gender stereotypes are cognitive structures containing socially shared knowledge and expectations about women and men. Research has found that the dimensions evaluation (sweetheart vs. bitch) and traditionality (businessman vs. stay-at-home dad) have high explanatory power for identifying gender stereotypes. As a pilot study, the current paper investigates the traditionality and evaluation perceptions of expressions for women and men in English and Spanish, analysing them in the framework of Conceptual Metaphor and Metonymy Theory. In an online questionnaire, university students in London and Madrid rated 20 expressions for women (e.g. Eng. bitch, Spa. princesa) and men (e.g. Eng. player, Spa. cabrón), previously produced by themselves in single brainstorming sessions. The results indicate the existence of gender stereotypes, especially regarding promiscuity, and a correlation between traditionality and evaluation. Surprisingly and contrary to previous research, female participants produce more promiscuous subtypes than male participants.
\end{abstract}

Keywords: gender stereotypes, production, perception, traditionality, evaluation, Conceptual Metaphor and Metonymy Theory 


\section{Introduction}

Gender stereotyping remains a pervasive issue in society. Gender stereotypes are cognitive structures containing socially shared knowledge and expectations about characteristics of women and men (Eckes, 2010, p. 178). While they overemphasize alleged differences between women and men regarding personality traits, capabilities and interests, they ignore actual variation. Stereotypically, women show greater communality, while men show greater agency (Ellemers, 2018, p. 277). When due to gender stereotypes, people are discriminated against and limited in their personal developments, achievements or life choices, sexism arises (Garaigordobil \& Aliri, 2013, p. 174). The omnipresent inequality issue of the gender pay gap is a well-known example of that.

Stereotyping is directly linked to and shared through language use:

Language reflects which categories are singled out as targets for stereotyping, and is one of the main carriers of stereotypic information we come to associate with these categories. (Beukeboom \& Burgers, 2019, p. 28)

One way of detecting gender stereotypes in language and thus human cognition is through metaphors and metonymies that refer to different types of women and men. According to Conceptual Metaphor Theory (Deignan, 2010; Kövecses, 2000; Lakoff \& Johnson, 1980), metaphor is not just a figure of speech but central to human cognition. Through metaphor, we conceptualize one domain (target domain) in terms of another (source domain). In Spanish, for example, a promiscuous woman (target concept) can be conceptualized as guarra 'sow' or zorra 'vixen' (source concepts). According to the Great Chain of Being (Lakoff \& Turner, 1989; Lovejoy, 1936) - an ontological folk hierarchy encompassing higher-order and lower-order entities, ranging from humans over animals and plants to mere objects - such metaphorical conceptualizations create a pejorative effect: The woman who, due to her sexual activity, is referred to as guarra 'sow', is denied her humanlike features and downgraded to not just any animal but the prototype of a dirty animal. Such degradation arising from the conceptual metaphor PROMISCUOUS WOMAN IS A DIRTY ANIMAL is a sign of prevalent gender stereotypes, according to which women, unlike men, are expected to be sexually passive and submissive or else they are regarded as impure and dirty (Reiss, 1967; Zaikman \& Marks, 2014; see Section 2). In Conceptual Metonymy Theory (Kövecses \& Radden, 1998; Lakoff \& Johnson, 1980), metonymy is seen as "one entity to refer to another that is related to it" (Lakoff \& Johnson, 1980, p. 35) with an emphasis on the 
contiguity of those entities on the extra-linguistic level. In contrast to metaphor, in metonymy the mapping occurs within a single domain (Lakoff \& Turner, 1989). An example is the conceptualization of the woman as a child in the metonymy GIRL for WOMAN, which is based on the timeline of a woman's life, denying her adulthood and infantilizing her to a cognitively and physically immature being (Pustka, 2015, p. 113). In Conceptual Metaphor and Metonymy Theory, culture plays a crucial role in the creation and perpetuation of culturespecific stereotypes and prejudices:

[C]onceptual metaphors emerge from the interaction between body and culture. While the body is a potentially universal source for emerging metaphors, culture functions as a filter that selects aspects of sensorimotor experience and connects them with subjective experiences and judgments for metaphorical mappings. That is, metaphors are grounded in bodily experience but shaped by cultural understanding. Put differently, metaphors are embodied in their cultural environment. (Yu, 2008, p.

In this present paper, two pilot studies on gender stereotypes are presented: The first one, a production study, investigates which types of women and men are produced by university students in London, United Kingdom and Madrid, Spain. These expressions are analysed in the framework of Conceptual Metaphor and Metonymy Theory. The second one, a perception study, investigates how the same students perceive the expressions most frequently produced in study 1 in terms of evaluation and traditionality. The results show that gender stereotyping appears to be prevalent in the conceptualizations of different types of women and men, especially when it comes to promiscuity. However, female participants seem to reject the sexual double standard according to which men and women are judged differently when it comes to casual sex. According to this standard, women are expected to be sexually passive while men can be sexually active.

Moreover, the results appear to show a correlation between the dimensions traditionality and evaluation: Women who are rated traditional are rated more positive than women who are rated non-traditional. While some results conform to findings of older studies, suggesting a lack of attitudinal changes, e.g. when it comes to the positive evaluation of traditional gender roles, other results indicate possible shifts in societal attitudes and perceptions, e.g. when it comes to embracing female promiscuity and sexual freedom. If larger studies were to detect these findings too, they could serve as important clues to understanding how gender-related attitudes both persist and evolve in society - especially when directly comparing two separate cultures. 


\section{Gender stereotypes}

Gender stereotypes are cognitive structures containing specific beliefs and expectations about the characteristics of women and men (Eckes, 2010, p. 178; Ellemers, 2018, p. 276; López-Sáez \& Lisbona, 2009, p. 364). Thus, gender stereotypes have two aspects to them: the descriptive and the prescriptive aspect. While descriptive gender stereotypes are based on beliefs about what women and men are like and how they behave in a certain culture, prescriptive gender stereotypes are based on beliefs about how women and men should be and behave (Rudman \& Glick, 2008, pp. 105-130). For example, according to descriptive gender stereotypes, women are emotional and understanding, whereas men are dominant and ambitious, and, according to prescriptive gender stereotypes, women should show emotions and compassion, whereas men should dominate others and work hard (Burgess \& Borgida, 1999, p. 666; Eckes, 2010, p. 178). A violation of the assumptions generated by descriptive stereotypes normally results in surprise; a violation of the assumptions generated by prescriptive stereotypes results in condemnation and social rejection (Rudman \& Glick, 2008, pp. 105-106). Even though society and gender roles are in constant development, gender stereotypes tend to be culturally invariant and highly resistant to change (Eckes, 2010, p. 178; Williams et al., 1999), though stereotypes about women seem to be more dynamic and likely to change than those about men (Diekman \& Eagly, 2000, p. 1183). For instance, over the past three decades, while their communality has remained the same, women have considered themselves as having become more agentic, while men have not considered themselves as having become more communal (Eckes, 2010, p. 179; Kite et al., 2008, p. 209). Additionally, societal and attitudinal changes happen more quickly compared to linguistic changes. Thus, language tends to represent conservative patterns that might already be outdated with regards to societal attitudes. Remaining in the language, these patterns can still influence the speakers' attitudes, making progress more difficult (Curzan, 2003, p. 188).

When gender stereotypes cause social inequality between women and men, sexism arises. In Ambivalent Sexism Theory (Glick \& Fiske, 1996), sexism is distinguished into benevolent sexism (BS) and hostile sexism (HS). While both favour traditional types of women, e.g. housewives and mothers, BS consists of praising such women - creating the women-are-wonderful-effect (Eagly \& Mladinic, 1994) -, whereas HS consists of opposing non-traditional types of women, e.g. career women, feminists, lesbians etc. (Ramos et al., 2018, p. 160). However, both BS and HS help perpetuate gender roles by rewarding role- 
conforming women with positive attitudes towards them and punishing role-non-conforming women with negative attitudes (Ramos et al., 2018, p. 160). Due to increasing awareness of political correctness, explicit expressions of negative attitudes towards non-traditional women have decreased, and people are now more likely to emphasize supposed positive qualities of traditional women, often not realising that benevolent sexist views are harmful too (Barreto \& Ellemers, 2015, p. 149). For example, they play a crucial role in rape victim blaming (Glick et al., 2002). Furthermore, Glick et al. (2000) found that high HS and BS mean values in a nation predict a high degree of gender inequality, and that women reject HS and endorse BS significantly more than men, the more sexist a nation is.

Stereotypical female characteristics include warmth, compassion, emotionality and passivity, while stereotypical male characteristics include competence, assertiveness, agency and competitivity (Ellemers, 2018, p. 277; Prentice \& Carranza, 2002). These stereotypes are considered global stereotypes, as they are extremely broad and heterogeneous. They consist of a set of subtypes representing more specific and homogeneous gender types, e.g. career women, housewives, athletes, sexual women, lesbians and feminists for women, and macho men, businessmen, athletes, family men, wimps and homosexual men for men (Carpenter \& Trentham, 1998, p. 680; Fiske et al., 2002, p. 879; Vonk \& Ashmore, 2003, pp. 257-258).

These subtypes can be identified and measured on different dimensions. Competence and warmth identify four groups of stereotypes, namely paternalistic (incompetent but warm), admiring (competent and warm), contemptuous (incompetent and cold), and envious stereotypes (competent but cold). Paternalistic stereotypes include elderly people, disabled people and housewives. They are disrespected and pitied and considered a non-threatening group. Admiring stereotypes include members of the in-group and close allies. Members are proud of their respect and status. Contemptuous stereotypes include welfare recipients and poor people, who are considered parasitic to society. Finally, envious stereotypes include Asians, Jews, rich people and feminists, who are considered too competent and not likeable (Fiske et al., 2002, pp. 880-881).

Another way of identifying different female and male subtypes is by clustering them according to the following dimensions: Firstly, the dimension evaluation highlights the difference between positive and negative perceptions of women (sweetheart vs. bitch) and men (businessman vs. nerd). Secondly, the dimension sexuality shows how sexual certain subtypes are seen (playboy vs. scholar). When referring to women, the dimension sexuality is further divided into respectability (mother vs. whore) and sexual attractiveness (babe vs. dyke). Lastly, the dimension traditionality represents the difference between traditional and 
non-traditional subtypes of women (e.g. housewife vs. career woman) and men (businessman vs. wimp) (Vonk \& Ashmore, 2003, p. 258).

Based on two pilot studies, this paper aims at showing which subtypes of women and men English and Spanish university students produce and how the same participants rate the most frequently produced expressions regarding evaluation and traditionality. This serves two functions: Firstly, it is possible to show which female and male subtypes are perceived by the participants to be traditional and non-traditional as well as positive and negative. More importantly, however, the relationship between the perceived traditionality and evaluation of certain subtypes can be detected.

\section{Hofstede's Cultural Dimensions Theory}

When comparing results obtained in the capitals of two countries, it is essential to highlight the importance of the differences between the respective cultures. To do so, the Cultural Dimensions Theory (Hofstede et al., 2010) can be helpful. The model proposed in this theory consists of six dimensions to measure a nation's cultural tendencies. Figure 1 shows the respective scores obtained by the United Kingdom and Spain on the six dimensions.

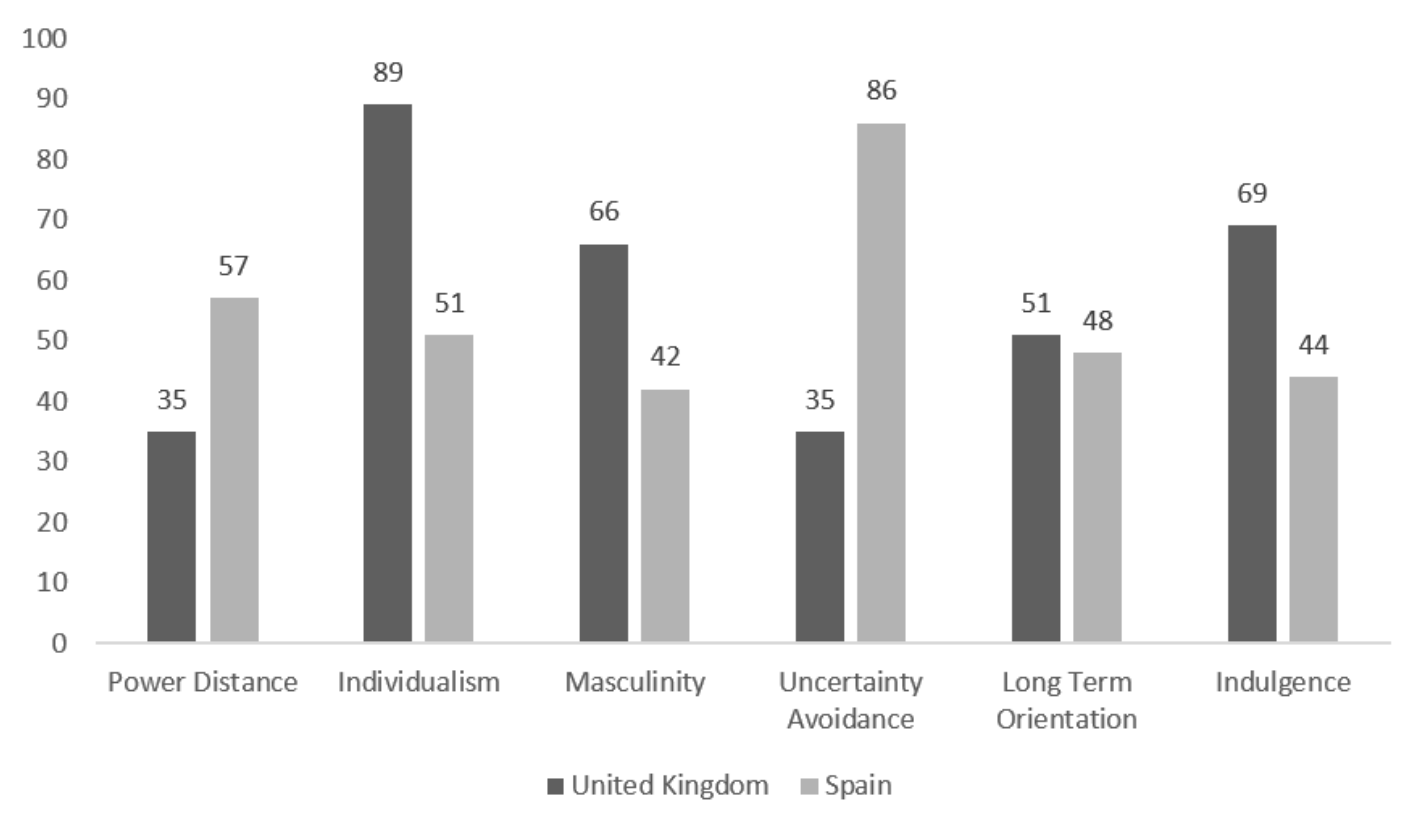

Figure 1. Cultural dimension scores of the United Kingdom and Spain (Hofstede et al., 2010).

When investigating attitudes towards gender, the dimension Masculinity is particularly interesting: A nation's degree of masculinity is thought to affect attitudes towards women and 
men who do (not) conform to traditional gender roles. According to the theory, cultures that are considered rather masculine, like the United Kingdom (66), tend to praise and positively evaluate traditional women and men, while they show a tendency to reject and negatively evaluate non-traditional subtypes (Hofstede et al., 2010, p. 158). Additionally, masculinity scores may predict attitudes towards female and male agency and responsibility. Thus, cultures with a rather high masculinity score, like the United Kingdom, tend to see men as agentic and responsible and women as passive, while cultures with a low masculinity score, like Spain (42) - despite the stereotype of the 'macho country' -, lean more towards seeing women and men as equally responsible and decisive (Hofstede et al., 2010, p. 159). This seems to also apply to sexual activity and promiscuity. While masculine cultures tend to support the sexual double standard, feminine cultures are more likely to reject it. However, when it comes to casual sex, attitudes seem to have changed in recent years. Young women appear to become more open about it and often reject the sexual double standard also in masculine cultures (Farvid et al., 2017, p. 556). When it comes to homosexuality, cultures with a rather high masculinity score tend to feel threatened by it and appear to reject it (Hofstede et al., 2010, p. 158).

Although Hofstede's model continues to be praised and cited by many scholars, it is important to point out the criticism that has been directed at it. Critics argue, for example, that Hofstede's findings are out-dated, that the identified dimensions are too few to adequately determine cultural differences and that his approach to culture is too homogenous and ignores differences within a culture (Eringa et al., 2015, pp. 187-188; Jones, 2007, p. 5). Additionally, Hofstede's model has limitations when applied to small sample sizes as acknowledged by Hofstede himself (Hofstede \& Minkov, 2013, p. 2). In the current study, the model must therefore be applied cautiously, keeping its constraints in mind. However, despite the wave of criticism that Hofstede's model has drawn, “it remains the most valuable piece of work on culture for both scholars and practitioners" (Jones, 2007, p. 7).

When attempting to compare the results obtained by speakers of two languages, it is of course not only important to consider the two cultures but also the specifics of the respective languages. Conducting a large-scale study on positivity biases in different languages, Dodds et al. (2015) found that - while all human language words possess a universal positivity bias the Spanish language is inherently more positive than the English language (p. 2391), as, on a nine-point scale from most negative/saddest to most positive/happiest, Spanish words were rated more positively by native speakers than the English equivalent words. Thus, this finding must be taken into consideration when analysing the results presented in this paper. 


\section{Methodology: Production and perception}

Two pilot studies on gender stereotypes - a production study and a perception study built upon the first study - were conducted. The participants of both studies were 12 university students in London, United Kingdom (English L1 speakers) and 12 in Madrid, Spain (Spanish L1 speakers) aged between 18 and 25 years (mean age: 19.7). The participants were 7 females and 5 males in London and 8 females and 4 males in Madrid. One female participant in London did not take part in the second study. However, her production data was still considered in the first study.

In the production study, participants engaged in spontaneous written single brainstorming sessions, in which they were asked to note down expressions for different subtypes of women and men on a blank sheet (see Figure 2). They were told to think of aspects such as a woman's or man's looks, personality traits, lifestyle choices and sexuality. There was no interference from the researcher regarding the design of the sheet. Afterwards, in recorded interviews, each participant was asked about the expressions they had come up with regarding meanings, connotations, frequencies, etc.

In the perception study, the same participants rated the 20 in the prior study most frequently mentioned expressions for women and men (ten each) in an online questionnaire created through LamaPoll. Only nine of the ten expressions each were in fact those most frequently mentioned in the production study. However, frequent colloquial expressions for the subtypes homosexual woman and homosexual man were included in the questionnaire (Eng. dyke and fag and Sp. bollera and maricón), as this specific subtype is widely discussed in gender stereotype research (e.g. Fiske et al., 2002; Green et al., 2005). Each expression for a specific subtype was rated on 15 slider scales relating to the following aspects: female/male typicality, violation of female/male role, freedom regarding behaviour, warmth, competence, strength, agency, age, respectability, evaluation and traditionality. An important role model for the scales was Green et al. (2005). The present paper focuses on the perception data obtained from two scales relating to evaluation and traditionality. The two extremes of the evaluation scale were labelled as not like the traditional female/male stereotype (Spanish: no como el estereotipo tradicional femenino/masculino) and like the traditional female/male stereotype (Spanish: como el estereotipo tradicional femenino/masculino.), respectively. The two extremes of the traditionality scale were labelled as bad person (Spanish: persona mala) and good person (Spanish: persona buena), respectively. The participants did not receive any 
further input as to how to interpret the scales. By investigating the perception data for the scales evaluation and traditionality, a likely correlation between the two dimensions can be tested, i.e. positive evaluation of traditional stereotypes and negative evaluation of nontraditional stereotypes - a correlation that has been confirmed in prior research (Glick \& Fiske, 1997; Ramos et al., 2018).

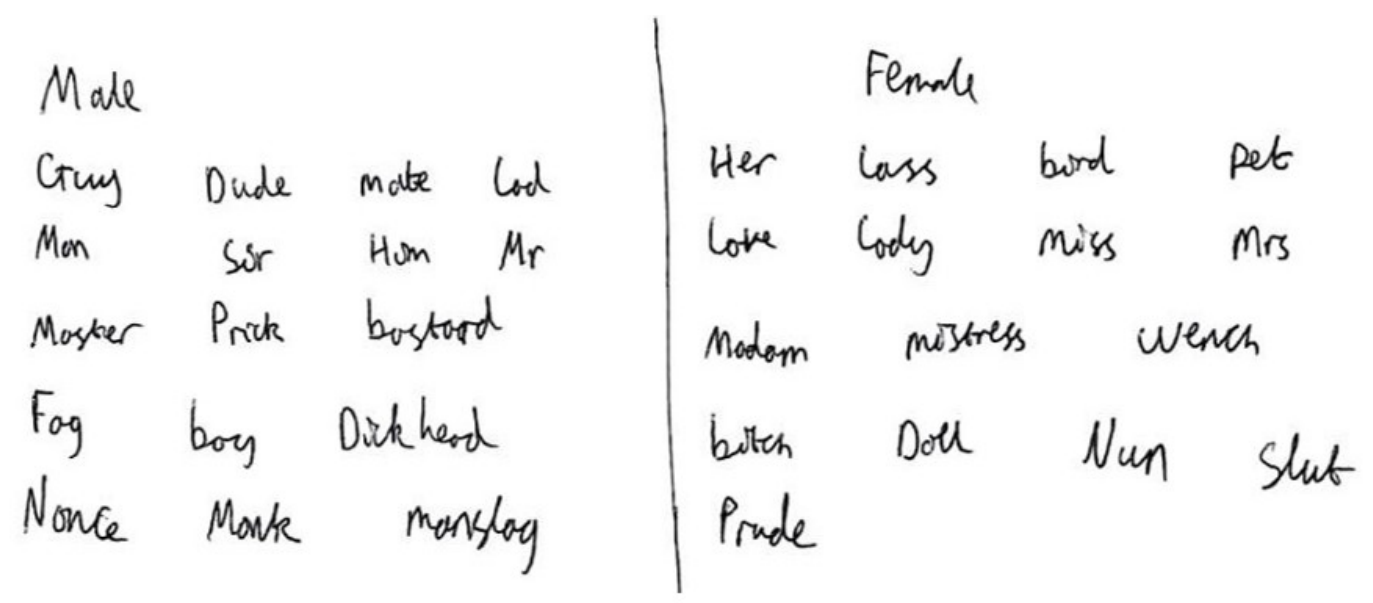

Figure 2. Example of a written brainstorming by a male participant in London.

\section{Results}

\subsection{Study 1: Production}

The numbers of tokens of expressions for women and men produced by the participants are shown in Table 1. All in all, the tendencies regarding the production of tokens conform to results obtained in other studies: Female participants tend to generate a bigger number of subtypes than men (Vonk \& Olde-Monnikhof, 1998, p. 41). 


\begin{tabular}{|l|l|l|l|}
\hline Location & Participants & Expressions for women & Expressions for men \\
\hline \multirow{3}{*}{ London } & all (12) & 140 tokens & 136 tokens \\
& & $(11.7 /$ participant) & (11.3/participant) \\
\cline { 2 - 4 } & female (7) & 88 tokens & 84 tokens \\
& & $(12.6 /$ participant) & (12/participant) \\
\cline { 2 - 4 } & male (5) & 52 tokens & 52 tokens \\
& & $(10.4 /$ participant) & (10.4/participant) \\
\hline Madrid & all (12) & 153 tokens & 166 tokens \\
& & $(12.8 /$ participant) & $(13.8 /$ participant) \\
\cline { 2 - 4 } & female (8) & 107 tokens & 111 tokens \\
& & $(13.4 /$ participant) & (13.9/participant) \\
\cline { 2 - 5 } & male (4) & 46 tokens & 55 tokens \\
& & $(11.5 /$ participant) & (13.8/participant) \\
\hline
\end{tabular}

Table 1. Numbers of tokens of expressions for women and men produced by the participants in London and Madrid.

Several different female and male subtypes were produced by the English and Spanish participants, which are shown in Tables 2, 3, 4 and 5.

\begin{tabular}{|l|l|l|l|}
\hline Female subtypes & Female participants & Male participants & Total \\
\hline $\begin{array}{l}\text { sexual/sexually attractive/ } \\
\text { promiscuous woman }\end{array}$ & 20 & 10 & 30 \\
\hline sweet woman/darling & 14 & 9 & 23 \\
\hline lady & 14 & 7 & 21 \\
\hline young woman/girl & 9 & 6 & 15 \\
\hline bitchy woman & 6 & 5 & 11 \\
\hline lesbian/feminist woman & 5 & 5 & 10 \\
\hline wife/mother/girlfriend/sister & 7 & 3 & 10 \\
\hline woman/female/she & 2 & 4 & 6 \\
\hline old/ugly woman & 5 & 0 & 5 \\
\hline beautiful woman & 3 & 1 & 4 \\
\hline prude woman & 1 & 2 & 3 \\
\hline heterosexual woman & 2 & 0 & 2 \\
\hline
\end{tabular}

Table 2. Female subtypes produced in London, with the number of tokens produced per subtype by female, male and all participants. 


\begin{tabular}{|l|l|l|l|}
\hline Female subtypes & Female participants & Male participants & Total \\
\hline friend/acquaintance & 24 & 10 & 34 \\
\hline young/weak woman/girl & 17 & 12 & 29 \\
\hline promiscuous woman & 15 & 3 & 18 \\
\hline lady & 6 & 8 & 14 \\
\hline woman/female/she & 8 & 4 & 12 \\
\hline sweet woman/darling & 5 & 4 & 9 \\
\hline beautiful woman & 8 & 0 & 8 \\
\hline ugly/vulgar woman & 5 & 1 & 6 \\
\hline dumb woman & 6 & 0 & 6 \\
\hline wife/mother/sister & 3 & 2 & 5 \\
\hline old woman & 2 & 1 & 3 \\
\hline intelligent/successful woman & 2 & 1 & 3 \\
\hline masculine woman & 2 & 0 & 2 \\
\hline overweight woman & 2 & 0 & 2 \\
\hline arrogant woman & 1 & 0 & 1 \\
\hline person & 1 & 0 & 1 \\
\hline
\end{tabular}

Table 3. Female subtypes produced in Madrid, with the number of tokens produced per subtype by female, male and all participants.

\begin{tabular}{|l|l|l|l|}
\hline Male subtypes & Female participants & Male participants & Total \\
\hline dumb/annoying man & 18 & 11 & 29 \\
\hline promiscuous man & 12 & 7 & 19 \\
\hline gay man/wimp & 12 & 3 & 15 \\
\hline guy & 10 & 5 & 15 \\
\hline sir/gentleman & 6 & 6 & 12 \\
\hline husband/father/boyfriend/brother & 6 & 3 & 9 \\
\hline man/male/he & 3 & 6 & 9 \\
\hline friend & 1 & 6 & 7 \\
\hline babe/darling & 7 & 0 & 7 \\
\hline boy & 4 & 3 & 7 \\
\hline successful man & 2 & 0 & 2 \\
\hline heterosexual man & 2 & 0 & 2 \\
\hline strong man & 1 & 0 & 1 \\
\hline child abuser & 0 & 1 & 1 \\
\hline chaste man & 0 & 1 & 1 \\
\hline
\end{tabular}

Table 4. Male subtypes produced in London, with the number of tokens produced per subtype by female, male and all participants. 


\begin{tabular}{|l|l|l|l|}
\hline Male subtypes & Female participants & Male participants & Total \\
\hline friend/acquaintance & 28 & 20 & 48 \\
\hline macho/promiscuous man & 17 & 5 & 22 \\
\hline young man & 12 & 9 & 21 \\
\hline sir/gentleman & 9 & 8 & 17 \\
\hline vulgar//ower class man & 6 & 3 & 9 \\
\hline man/male/he & 5 & 2 & 7 \\
\hline person & 5 & 1 & 6 \\
\hline husband/father/boyfriend/brother & 4 & 2 & 6 \\
\hline dumb man & 6 & 0 & 6 \\
\hline intelligent/successful man & 3 & 3 & 6 \\
\hline tall/strong man & 5 & 0 & 5 \\
\hline handsome man & 5 & 0 & 5 \\
\hline gay/submissive man & 3 & 1 & 4 \\
\hline overweight man & 2 & 0 & 2 \\
\hline nerd & 1 & 0 & 1 \\
\hline old man & 0 & 1 & 1 \\
\hline
\end{tabular}

Table 5. Male subtypes produced in Madrid, with the number of tokens produced per subtype by female, male and all participants.

Overall, the results conform to those of comparable studies regarding the subtypes produced (e.g. Carpenter \& Trentham, 1998; Vonk \& Ashmore, 2003). Unsurprisingly and in line with other studies (e.g. Vonk \& Ashmore, 2003, p. 261), participants produce more tokens of the subtype friend in their own gender in-group. In Madrid, for example, the male subtype friend is produced 3.5 times per female participant compared to 5.0 times per male participant. However, some tendencies differ from those detected in prior studies. While past studies have found that men generate more subtypes of women and men regarding their sexual activity (e.g. Carpenter \& Trentham, 1998, p. 692; Vonk \& Ashmore, 2003, p. 264), the female participants of the current study produced more tokens of the subtypes promiscuous woman (e.g. Eng. slut, slag, whore, Sp. guarra, puta, zorra) and promiscuous man (e.g. Eng. lad, player, fuckboy, Sp. macho, mujeriego, cabrón) than male participants. This result might be in line with the trend of women's changing attitudes towards casual sex in recent years. They seem to become more open about it or wish to appear more open about it on the surface, even when still perpetuating sexual double standard discourse (Farvid et al., 2017, p. 556). Female participants might therefore be keen to produce promiscuous subtypes. Since the two studies mentioned above were conducted twenty-two and seventeen years ago, there is reason to believe that attitudinal changes might be responsible for the divergent results.

The most frequently produced expressions for different subtypes of women and men in London and Madrid are shown in Table 6 (see Appendix for the less frequently produced 
expressions). The numbers in brackets indicate how many of the twelve participants in London and Madrid produced each expression. In the Spanish grammar system, there are masculine and feminine versions of most nouns denoting people differing only in their ending (either $-a$ or $-o /-e /-\varnothing$ ). Thus, if a participant thinks of chica during the brainstorming, they are likely to then also think of chico. The respective occurrences in the Spanish data are tíaltio, chicalchico, señora/señor, niña/niño, piba/pibe, and chavala/chaval. This is of course not the case in English. The expressions in Table 6 were those included in the English and Spanish online questionnaires for the perception study (see 5.2).

\begin{tabular}{|c|c|c|c|}
\hline $\begin{array}{l}\text { Expressions for } \\
\text { women, London } \\
\text { (EWL) }\end{array}$ & $\begin{array}{l}\text { Expressions for } \\
\text { men, London } \\
\text { (EML) }\end{array}$ & $\begin{array}{l}\text { Expressions for } \\
\text { women, Madrid } \\
\text { (EWM) }\end{array}$ & $\begin{array}{l}\text { Expressions for } \\
\text { men, Madrid } \\
\text { (EMM) }\end{array}$ \\
\hline slut $(11 / 12)$ & $\operatorname{lad}(9 / 12)$ & tía $(8 / 12)$ & chico $(8 / 12)$ \\
\hline bitch $(11 / 12)$ & guy $(8 / 12)$ & chica $(8 / 12)$ & señor $(8 / 12)$ \\
\hline $\operatorname{girl}(7 / 12)$ & boy $(7 / 12)$ & señora $(6 / 12)$ & chaval $(6 / 12)$ \\
\hline $\operatorname{slag}(6 / 12)$ & mate $(4 / 12)$ & niña $(6 / 12)$ & tio $(6 / 12)$ \\
\hline$M s(5 / 12)$ & $\operatorname{Mr}(4 / 12)$ & $p i b a(5 / 12)$ & macho (5/12) \\
\hline $\operatorname{Mrs}(5 / 12)$ & $\operatorname{dick}(4 / 12)$ & guarra $(5 / 12)$ & niño (5/12) \\
\hline $\operatorname{lady}(5 / 12)$ & $\operatorname{Sir}(4 / 12)$ & chavala $(5 / 12)$ & pibe (4/12) \\
\hline whore $(5 / 12)$ & player (4/12) & señorita $(5 / 12)$ & colega $(4 / 12)$ \\
\hline babe (5/12) & dude (4/12) & princesa $(4 / 12)$ & cabrón (4/12) \\
\hline dyke (2/12) & fag $(2 / 12)$ & bollera $(0 / 12)$ & maricón $(2 / 12)$ \\
\hline
\end{tabular}

Table 6. Most frequently produced expressions for different subtypes of women and men. Occurrences are indicated in brackets.

The most frequently produced expressions are mostly metaphorical or metonymic, as identified by the Metaphor Identification Procedure (Pragglejaz Group, 2007) and an adapted procedure for metonymy identification (Biernacka, 2013) in which contextual meaning and basic meaning of a lexical item are contrasted with each other to determine whether an item is metaphorical or metonymic. This was done with the online versions of the Oxford English Dictionary (OED) and the Diccionario de la lengua española de la Real Academia Española (DRAE) respectively. The only expressions identified as non-metaphorical or non-metonymic were Eng. Ms, Mrs, lady, dyke, mate, Mr and Sir (7 out of 20 expressions), and Sp. señora, señorita and señor (3 out of 20 expressions).

The big majority of conceptualizations of the woman and man is as a child, employing the metonymy CHILD/GIRL/BOY for WOMAN/MAN (see Section 1). The respective expressions are Eng. girl and babe and Sp. chica, niña, piba and chavala for a woman, and Eng. boy and Sp. chico, chaval, niño and pibe for a man. All these expressions refer in their basic meanings 
to a child or minor. Yet, they figuratively and mostly colloquially refer to adult women and men, often as forms of address. In London, a female young subtype is produced 12 times and a male young subtype 7 times among the most frequent expressions, while the Spanish participants produce a female young subtype 24 times and a male young subtype 23 times. Conceptualizing an adult as a child can result in belittling the person by depriving them of their fully developed cognitive and bodily functions (see Section 1). However, such forms of address can also create proximity between addresser and addressee, especially so in youth language (Díaz Pérez, 1997; Neuland, 2008; Rodríguez González, 2002). The same holds true for Sp. tía and tio. While their basic meanings are 'aunt' and 'uncle', they are used to refer to a person unrelated to the speaker (Díaz Pérez, 1997, p. 197).

The subtypes promiscuous woman and promiscuous man are conceptualized in several ways. In the following, the basic meanings of the expressions are indicated in inverted commas. A promiscuous woman is conceptualized as Eng. slut 'dirty, untidy woman', slag 'by-product of smelting ore', whore 'prostitute', and Sp. guarra 'sow'; a promiscuous man, on the other hand, is conceptualized as Eng. lad 'young fellow', player 'person taking part in a sport or game', Sp. macho 'male', and cabrón, the augmentative of cabro 'billy goat'. The difference regarding the conceptualizations is striking. While the promiscuous woman is conceptualized in terms of a dirty, piggish and undesired prostitute, the promiscuous man is conceptualized as a rather neutral male whose sex life is considered a sporty game, and as a billy goat, i.e. a male goat that naturally mates with several or all females of its herd. Thus, promiscuity in women tends to be regarded as an objectionable profession but as a healthy, natural hobby in men.

The subtype homosexual woman is conceptualized as Sp. bollera 'woman who makes or sells buns', derived from bollo 'bun' to metaphorically refer to the vagina (similarity in shape) and metonymically also to the woman (PART for WHOLE), and the subtype homosexual man as Eng. fag, an abbreviation of faggot 'troublesome, slatternly woman' (Johansson, 1981), and Sp. maricón, the augmentative of marica, which itself is the diminutive of the prototypical female Christian name Maria. Thus, while the homosexual woman referred to as bollera is identified as such by focussing solely on the importance of sexual intercourse, the homosexual man is considered a woman.

Other conceptualizations of a woman are Eng. bitch 'female dog' to denote a spiteful woman, and Sp. princesa 'princess' to refer to a very good-looking woman. While the derogatory bitch reduces a woman to an animal, i.e. to a lower category of the Great Chain of Being, princesa elevates a woman to nobility, i.e. a higher category. 
The remaining conceptualizations of a man are Eng. guy, derived from the historical figure Guy Fawkes and later meaning 'person of grotesque appearance', to refer to a man, and dick 'penis' to derogatorily refer to a contemptible man by employing the metonymy PENIS for MAN, dude 'stylish man' to refer to any man, as well as Sp. colega 'colleague' to refer to a friend, mitigating the closeness between individuals. It should be noted that the expression guy has since lost the meaning of grotesque appearance and can now be used in plural to address both men and women, e.g. when addressing a group of male and female friends with "Hi, guys". When it comes to the expression dick, the conceptualization is especially interesting as a man's annoying behaviour seems to be attributed to his penis - a body part that is considered to be inextricably linked to maleness.

Naturally, not all expressions for subtypes of women and men are equally conventionalised. All the 20 most frequently mentioned English expressions have entries in the OED, and all the 20 most frequently mentioned Spanish expressions have entries in the DRAE, except for cabrón 'promiscuous man'. However, not all the other less frequently mentioned expressions (see Appendix) have entries in the respective dictionary: 6 out of 64 types of EWL (9.4\%) and 10 out of 74 types of EML (13.5\%) do not have entries in the OED, and 25 out of 84 types of EWM (29.8\%) and 35 out of 101 types of EMM (34.7\%) do not have entries in the DRAE. On the one hand, these percentages indicate the degree of conventionalisation of (colloquial) expressions. On the other hand, the differences are to a certain degree due to different normative dictionary traditions and the overall size of the dictionaries. The OED has at least twice as many entries as the DRAE. These issues highlight the importance of spontaneous brainstorming sessions with L1 speakers for the elicitation of such expressions as participants produce expressions regardless of dictionary traditions.

Additionally, perception studies play a crucial part in research like this since they can determine subtle differences in the connotations of expressions and in the speakers' attitudes towards them. For example, a female participant from London reported no differences between slut and slag in the interview but rated slut as less traditional and more negative than slag in the online questionnaire.

\subsection{Study 2: Perception}

\subsubsection{Traditionality}

The approximate mean results for traditionality for each of the 40 words (20 English and 20 Spanish words, of which 10 words each for women and men) are shown in Table 7. Low means indicate not like the traditional female/male stereotype, high means indicate like 
the traditional female/male stereotype. The Spanish equivalents are no como el estereotipo tradicional femenino/masculino and como el estereotipo tradicional femenino/masculino.

\begin{tabular}{|l|l|l|l|}
\hline EWL & EML & EWM & EMM \\
\hline Mrs: 89.7 & Mr: 91.4 & señora: 86.4 & señor: 82.4 \\
\hline lady: 81.5 & guy: 86.7 & señorita: 78.8 & macho: 65.7 \\
\hline girl: 70.5 & lad: 71.1 & princesa: 67.3 & chico: 59.5 \\
\hline Ms: 52.7 & mate: 70.5 & niña: 65.4 & chaval: 58.1 \\
\hline babe: 51.1 & player: 65.6 & chica: 63.8 & tio: 58.1 \\
\hline bitch: 32.6 & Sir: 64.9 & tía: 56.8 & niño: 54.3 \\
\hline slut: 25.1 & dude: 60.1 & piba: 45.0 & colega: 44.6 \\
\hline slag: 21.5 & boy: 45.6 & chavala: 44.3 & cabrón: 44.1 \\
\hline whore: 17.6 & dick: 44.6 & guarra: 25.3 & pibe: 39.0 \\
\hline dyke: 14.6 & fag: 10.6 & bollera: $: 8.1$ & maricón: 5.8 \\
\hline
\end{tabular}

Table 7. Participants' mean ratings of the dimension traditionality. Low means indicate low traditionality, high means indicate high traditionality.

EML scores the highest mean result (61.1), followed by EWM (54.1), EMM (51.2) and EWL (45.7). EWL is in fact the only category where the mean result of less than 50 suggests an overall tendency for participants to produce more non-traditional than traditional female subtypes. The bigger difference between EWL and EML compared to the Madrid results could possibly be explained by the different scores of the United Kingdom and Spain on the dimension Masculinity (see Section 3). In rather masculine countries, like the United Kingdom, women and men tend to be considered inherently different while rather feminine countries, like Spain, show a greater tendency to consider women and men equal.

The most traditional subtypes are Eng. Mrs (89.7), lady (81.5), guy (86.7), Mr (91.4) and Sp. señora (86.4) and señor (82.4). Interestingly, while in English the most traditional subtype is the male $M r$, in Spanish it is the female señora. Regarding the expressions denoting children or young people, the female subtypes tend to be rated more traditional (Eng. girl: 70.5, babe: 51.1, Sp. chica: 63.8, niña: 65.4, piba: 45.0, chavala: 44.3) than the male subtypes (Eng. boy: 45.6, Sp. chico: 59.5, niño: 54.3; pibe: 39.0, chaval: 58.1). This might mean that women tend to be regarded as inherently younger than men. An indication for this could be that the youngest subtype babe is among the most frequently produced expressions for women, but not for men. The infantilization of women has been shown in previous research, e.g. in the contexts of sports (Spencer, 2003) or reproductive health (Cook et al., 2010). The comment of a female participant in the current study when comparing the connotations of girl and boy also points to female, as opposed to male, infantilization: "It's used in kind of a patronising context for girls but not for boys." 
Turning to the other end of the traditionality scale, in London but especially in Madrid, participants perceive the homosexual woman and man as the least traditional subtypes (Eng. dyke: 14.6, fag: 10.6, Sp. bollera: 8.1, maricón: 5.8). Additionally, the English and Spanish participants rate the homosexual man as less traditional than the homosexual woman. This is expected since

it seems that [homosexual] males are more easily seen as trespassing the psychological threshold for maleness $[\ldots]$ than vice versa. In other words, there may be a wider range of ways to be feminine than there are ways to be masculine. (Vonk \& Ashmore, 2003, p. 275)

A homosexual man is less likely to be considered traditional than a homosexual woman, while both are considered extremely non-traditional.

When it comes to the subtypes promiscuous woman and promiscuous man, the results are fundamentally different (see Table 7). Participants rate the promiscuous woman as much less traditional (Eng. slut: 25.1, slag: 21.5, whore: 17.5, Sp. guarra: 25.3) than the promiscuous man (Eng. lad: 71.1, player: 65.6, Sp. macho: 65.7, cabrón: 44.1). These findings are in line with the literature (e.g. Green et al., 2005, pp. 452-455; Vonk \& Ashmore, 2003, p. 277). An explanation for this rating is the prevalence of a sexual double standard (Reiss, 1967; Zaikman \& Marks, 2014), according to which it tends to be more acceptable for men to be sexually active and engage in promiscuous behaviour than for women. Furthermore, there is an overall tendency for male compared to female participants to rate female and male promiscuous subtypes as less traditional.

\subsubsection{Evaluation}

In Table 8, the approximate mean results for the dimension evaluation are shown. Low means indicate bad person, high means indicate good person. The Spanish equivalents are persona mala and persona buena. 


\begin{tabular}{|l|l|l|l|}
\hline EWL & EML & EWM & EMM \\
\hline babe: 70.0 & mate: 74.0 & princesa: 83.9 & colega: 77.6 \\
\hline lady: 62.3 & Mr: 56.2 & niña: 76.3 & niño: 69.5 \\
\hline Mrs: 61.6 & guy: 55.7 & señorita: 75.8 & señor: 56.5 \\
\hline girl: 60.5 & Sir: 54.0 & señora: 69.9 & maricón: 55.5 \\
\hline dyke: 56.7 & boy: 53.6 & chica: 65.1 & tío: 55.1 \\
\hline Ms: 54.8 & dude: 53.4 & bollera: 58.9 & pibe: 53.8 \\
\hline slut: 46.5 & fag: 52.0 & tía: 58.3 & chaval: 53.1 \\
\hline slag: 41.1 & lad: 44.5 & chavala: 50.7 & chico: 51.6 \\
\hline whore: 40.4 & player: 35.8 & piba: 46.1 & macho: 42.7 \\
\hline bitch: 18.4 & dick: 24.5 & guarra: 38.9 & cabrón: 9.4 \\
\hline
\end{tabular}

Table 8. Participants' mean ratings of the dimension evaluation. Low means indicate negative evaluation, high means indicate positive evaluation.

The London participants perceive babe as the most positive female subtype (70.0) and mate as the most positive male subtype (74.0), while they rate bitch as the most negative female subtype (18.4) and dick as the most negative male subtype (24.5). One female participant's comment on bitch illustrates this perceived negativity: "It would be the worst generic word for a woman if you wanted to offend her." The Madrid participants rate princesa as the most positive (83.9) and guarra as the most negative female subtype (38.9), and colega as the most positive (77.6) and cabrón as the most negative male subtype (9.4). In Madrid, thus, the most positively rated subtype is a female subtype, whereas the most negatively rated subtype is a male subtype, i.e. contrary to the London results. Interestingly, among the Spanish expressions for women, half of them are rated as positive (65 or higher), namely chica (65.1), señora (69.9), señorita (75.8), niña (76.3) and princesa (83.9). Among the Spanish expressions for men, only niño (69.5) and colega (77.6) are rated positively, while babe (70.0) and mate (74.0) are the only positively rated English expressions. As mentioned above, this is in line with findings by Dodds et al. (2015) that Spanish is inherently more positive than English (p. 2391).

Regarding the expressions denoting children or young people, in London the female terms are evaluated more positively than the male counterpart: girl (60.5) and babe (70.0) vs. boy (53.6). This could be an indication of positive attitudes towards the infantilization of women as opposed to men. Put bluntly, the woman as a minor and in need of assistance is favoured more than the male counterpart. Interestingly, the infantilised woman is also considered more traditional than the infantilised man - both in London and Madrid (see 5.2.1). Regarding the evaluation of young subtypes, however, in Madrid the results are balanced: chica (65.1) vs. chico (51.6), niña (76.3) vs. niño (69.5), piba (46.1) vs. pibe (53.8), 
and chavala (50.7) vs. chaval (53.1). This difference between London and Madrid can potentially be explained with the cultural dimension Masculinity (see Section 3). Thus, cultures with a rather high masculinity score, like the United Kingdom, tend to see men as mature and women as immature individuals.

Focusing on the perception results of only the promiscuous subtypes, interesting patterns emerge. In London, the female slut is rated most positively (46.5), followed by the male lad (44.5), the female subtypes slag (41.1) and whore (40.4) and finally the male player (35.8). In Madrid, the male macho is rated most positively (42.7), followed by the female guarra (38.9) and the male cabrón (9.4). In other words, English and Spanish participants evaluate the male promiscuous subtype as more negative than the female one. However, most participants - in Madrid especially - are female themselves and the participant's gender tends to play a crucial role in evaluating promiscuity among the gender in- and out-group. Moreover, in Madrid, guarra, macho and cabrón are the three most negatively rated expressions. In London, however, it is not the promiscuous subtypes that are rated most negatively but bitch, a spiteful woman, and dick, a contemptible man. This tendency also remains the same when looking at the individual evaluation means for the promiscuous subtypes of all four categories: EWL (42.7), EML (40.2), EWM (38.9) and EMM (26.1).

The evaluation of the homosexual subtypes is similar, namely rather neutral or positive, across all four categories: dyke (56.7), fag (52.0), bollera (58.9) and maricón (55.5). However, participants rate the homosexual woman more positively than the homosexual man, which corresponds to previous findings (Monto \& Supinski, 2014; Schope \& Eliason, 2004). Furthermore, the Spanish participants perceive both the female and the male homosexual subtype as more positive than the English participants. Again, this can be explained by considering the cultural dimension Masculinity (see Section 3). Cultures with a rather high masculinity score, like the United Kingdom, tend to feel threatened by homosexuality more than feminine cultures do and therefore reject it.

Looking at the results of all participants, a correlation between traditionality and evaluation can be observed in both London (0.41) and Madrid (0.34). It seems that the more traditional the participants perceive a subtype to be, the more positively they perceive it. The fact that this correlation is stronger in London can again be explained by the dimension Masculinity (see Section 3). As a more masculine country, the United Kingdom might show the tendency to praise traditional women and men, evaluating them positively, and to reject non-traditional women and men, evaluating them negatively. 
When it comes to promiscuous subtypes, male participants in London perceive all female subtypes to be more negative than female participants (slut: 41.2 vs. 51.0, slag: 39.0 vs. 42.8 , whore: 34.0 vs. 45.7$)$, while female participants rate player more negatively (34.2 vs. 37.8) but lad more positively (45.7 vs. 43.0). This overall tendency conforms to the results obtained by Milhausen and Herold (2001) in that people rate promiscuous subtypes of their own gender in-group more positively than the out-group. In Madrid, this tendency can only really be detected in cabrón, which females perceive as more negative than males (7.8 vs. 12.8), and very slightly in guarra, which females perceive as more positive than males (39.0 vs. 38.8). Apart from in-group favouritism and negative attitudes towards out-groups, research has shown that people distinguish further between in-subgroups and out-subgroups (Vonk \& Olde-Monnikhof, 1998). So, a chaste person generally has negative attitudes towards promiscuous women and men but positive attitudes towards chaste women and men and vice versa. Since the participants in this pilot study were not asked about their own personalities or behaviours, it is unknown whether they see themselves belonging to the promiscuous or any other subtype.

Regarding the most positively evaluated female subtypes, male participants - in London especially - tend to evaluate subtypes perceived to be very traditional, e.g. Mrs and $l a d y$, more positively than female participants (Mrs: 65.8 vs. 58.2, lady: 65.8 vs. 59.3). In relation to this, one female participant reported to perceive a patronising connotation when being called lady. When it comes to the least traditional subtypes, e.g. slut and whore, male participants - especially in London - evaluate most of the expressions more negatively than female participants (slut: 41.2 vs. 51.0 , bitch: 16.4 vs. 20.0 , slag: 39.0 vs. 42.9 , whore: 34.0 vs. 45.7 , dyke: 54.6 vs. 58.5 ). This trend is also revealed by the gender-dependent correlations between traditionality and the evaluation of female subtypes. There is a correlation of 0.73 in the results of the male participants compared to a correlation of 0.40 in the results of the female participants. These results, then, seem to conform to findings in Ambivalent Sexism Theory that men tend to obtain higher results than women in both HS and BS (Garaigordobil $\&$ Aliri, 2013). Thus, men generally favour traditional female subtypes more than women, but also show more hostility towards non-traditional female subtypes. It appears that this trend cannot be detected in Madrid. Here, the results of the female participants show a correlation of 0.70 and the results of the male participants show a correlation of 0.50 . A possible explanation might again be the cultural dimension Masculinity (see Section 3).

When it comes to the correlation between traditionality and evaluation of male subtypes, in London, the results of the male participants show a correlation of 0.44 , while 
those of the female participants show almost no correlation (0.05). In Madrid, in the results of the male participants there is a correlation of 0.26 , while those of the female participants even show a negative correlation (-0.07). Thus, consistent with the dimension Masculinity (see Section 3), male participants in London seem to favour traditional male subtypes more than male participants in Madrid.

\section{Discussion and conclusion}

The results of the pilot studies presented in this paper offer plenty of opportunity for interpretation and discussion. When it comes to the participants' production of female and male subtypes, a striking finding is that female, not male participants, in both London and Madrid, produce more items per person for both promiscuous woman and promiscuous man. As mentioned above, this tendency is contrary to results obtained in previous studies (e.g. Carpenter \& Trentham, 1998, p. 692; Vonk \& Ashmore, 2003, p. 264). It might indicate that young women are becoming more open about casual sex and are rejecting the sexual double standard (see Section 2). The fact that female participants perceive the subtype promiscuous woman as more positive than promiscuous man might be additional evidence for this trend. However, in terms of judging the traditionality of promiscuous subtypes, all, though especially the male, participants perceive the female subtype as less traditional than the male subtype. This tendency also reveals itself in the conceptualizations of promiscuous subtypes found among the most frequently produced expressions in study 1. As analysed above (see 5.1), the promiscuous woman is conceptualized as a dirty and undesired prostitute, while the promiscuous man is seen as a generic man with casual sex as a healthy, natural hobby. So, while female participants seem to be open about promiscuity in women and show positive attitudes towards it, they still appear to perceive them as less traditional than promiscuous men and tend to produce conservative conceptualizations reinforcing the sexual double standard of the sexually passive woman vs. the sexually active man. The conceptualizations of the subtypes promiscuous woman and promiscuous man, but also of the other subtypes in the current study (see 5.1), nicely highlight the crucial role that conceptual metaphor and metonymy play in reflecting and reinforcing gender stereotypes. Accordingly, through these two conceptual mechanisms, promiscuity is conceptualized as dirty behaviour in women but as a healthy activity in men, and the conceptualizations of female homosexuality emphasize the role of sexual intercourse between women, while male homosexuality is equated with womanhood, for example. 
When it comes to the homosexual types, their evaluation rating is neutral to slightly positive (see 5.2.2), while their traditionality rating is very low (see 5.2.1). In fact, they are considered so non-traditional that for the most part they were not even produced in the brainstorming. This is potential evidence for the peripheral place of the homosexual subtypes in the ad hoc production of female and male subtypes (Vonk \& Ashmore, 2003, pp. 262-263). Additionally, when asked after the brainstorming sessions why the participants had not listed any expressions specifically denoting homosexual women and men, they often responded that they had not thought of sexualities other than heterosexuality. Of course, a shortcoming of the pilot study was that participants were not asked about their own gender identity. It is possible that most of the participants were heterosexual and therefore did not regard the homosexual subtype as prototypical.

As mentioned before, there seems to be an overall correlation between traditionality and evaluation. However, as mentioned in Section 2, over the years the rejection of nontraditional women (HS) has decreased, while the appreciation of traditional women (BS) is still prevalent. It appears that this trend can be detected in the results of the current study, too. Male participants evaluate the subtypes of women which they rate most traditional more positively than those they rate least traditional. On average, when it comes to evaluation, a traditional female subtype is rated 65.8 by male participants in London and 71.6 in Madrid, while a non-traditional female subtype is rated 37.0 by male participants in London and 51.7 in Madrid. Thus, the evaluation of traditional subtypes approaches the positive extreme of 100 more than the evaluation of non-traditional subtypes, which approaches the negative extreme of 0 . This might be a sign for a stronger BS prevalence compared to a weaker HS prevalence among the male participants. Again, the dimension Masculinity (see Section 3) could explain the smaller difference between the ratings of traditional and non-traditional female subtypes and the overall more positive ratings of female subtypes in the more feminine Spanish culture compared to the more masculine culture of the United Kingdom. Additionally, the difference between the Spanish and the English ratings could be due to, as mentioned above, Spanish being inherently more positive than English (Dodds et al., 2015, p. 2391).

Since the present pilot study is based on the production and perception data of a small sample of participants, the results obtained must be regarded keeping this in mind. Additionally, it is important to consider that the participants belonged to only one age group (18 to 25 years), the gender distribution among the participants was uneven and the participants' sexual identity was unknown. Furthermore, while recruiting the same 
participants for both the production and the perception study is beneficial in some respects, it could have also led to learning effects that might have skewed the ratings.

Many results obtained in the current pilot study conform to findings of previous studies, whereas some do not. An important finding of the current study is that female participants produce more items per person for promiscuous subtypes. Since this is contrary to the results of previous studies, it would be beneficial to investigate whether this tendency remains the same in large-scale studies to detect current attitudinal changes in society. The same is the case for the evaluation results regarding homosexual subtypes. A larger study with participants of different age groups could reveal whether attitudes towards non-traditional female and male subtypes are indeed changing in a way that discriminated subgroups are being evaluated increasingly more positively. The growing popularity of Gay Pride parades in London, Madrid and many other cities among the LGBTQ+ community but also among people outside of this community would speak for this trend. Furthermore, as was the case in the present pilot study, it is recommendable for future research to focus on more than one language and culture in order to not only be able to draw conclusions regarding a single culture but also compare cross-cultural gender role attitudes and perceptions. The results of such studies could thus be important indicators for understanding the way in which genderrelated attitudes both persist and evolve in society as well as the role that conceptual metaphor and metonymy play in reflecting and reinforcing gender stereotypes, beliefs and prejudices.

\section{References}

Barreto, M., \& Ellemers, N. (2015). Detecting and experiencing prejudice: New answers to old questions. Advances in Experimental Social Psychology, 52, 139-219.

Beukeboom, C. J., \& Burgers, C. (2019). How stereotypes are shared through language: A review and introduction of the Social Categories and Stereotypes Communication (SCSC) framework. Review of Communication Research, 7, 1-37.

Biernacka, E. (2013). The role of metonymy in political discourse. Unpublished PhD thesis. Milton Keynes: The Open University.

Burgess, D., \& Borgida, E. (1999). Who women are, who women should be: Descriptive and prescriptive gender stereotyping in sex discrimination. Psychology, Public Policy, and Law, 5(3), 665-692.

Carpenter, S., \& Trentham, S. (1998). Subtypes of women and men: A new taxonomy and an exploratory categorical analysis. Journal of Social Behavior and Personality, 13(4), 679-696.

Cook, R. J., Cusack, S., \& Dickens, B. M. (2010). Unethical female stereotyping in reproductive health. International Journal of Gynecology \& Obstetrics, 109(3), 255-258.

Curzan, A. (2003). Gender shifts in the history of English. Cambridge: Cambridge University Press. 
Deignan, A. (2010). The cognitive view of metaphor: Conceptual metaphor theory. In L. Cameron \& R. Maslen (Eds.), Metaphor analysis: Research practice in Applied Linguistics, Social Sciences and the Humanities (pp. 44-56). London: Equinox.

Díaz Pérez, J. C. (1997). Sobre la gramaticalización en el tratamiento nominal. Revista de Filología Románica, 14(1), 193-209.

Diccionario de la lengua española de la Real Academia Española. Retrieved from http://dle.rae.es.

Diekman, A. B., \& Eagly, A. H. (2000). Stereotypes as dynamic constructs: Women and men of the past, present, and future. Personality and Social Psychology Bulletin, 26(10), 1171-1188.

Dodds, P. S., Clark, E. M., Desu, S., Frank, M. R., Reagan, A. J., Williams, J. R., .. Danforth, C. M. (2015). Human language reveals a universal positivity bias. Proceedings of the National Academy of Sciences, 112(8), 2389-2394.

Eagly, A. H., \& Mladinic, A. (1994). Are people prejudiced against women? Some answers from research on attitudes, gender stereotypes, and judgments of competence. European Review of Social Psychology, $5(1), 1-35$.

Eckes, T. (2010). Geschlechterstereotype: Von Rollen, Identitäten und Vorurteilen. In R. Becker \& B. Kortendiek (Eds.), Handbuch Frauen- und Geschlechterforschung: Theorie, Methoden, Empirie (pp. 178-189). Wiesbaden: Springer.

Ellemers, N. (2018). Gender stereotypes. Annual Review of Psychology, 69, 275-298.

Eringa, K., Caudron, L. N., Rieck, K., Xie, F., \& Gerhardt, T. (2015). How relevant are Hofstede's dimensions for inter-cultural studies? A replication of Hofstede's research among current international business students. Research in Hospitality Management, 5(2), 187-198.

Farvid, P., Braun, V., \& Rowney, C. (2017). 'No girl wants to be called a slut!': Women, heterosexual casual sex and the sexual double standard. Journal of Gender Studies, 26(5), 544-560.

Fiske, S. T., Cuddy, A. J. C., Glick, P., \& Xu, J. (2002). A model of (often mixed) stereotype content: Competence and warmth respectively follow from perceived status and competition. Journal of Personality and Social Psychology, 82(6), 878-902.

Garaigordobil, M., \& Aliri, J. (2013). Ambivalent sexism inventory: Standardization and normative data in a sample of the Basque Country. Behavioral Psychology/Psicología Conductual, 21(1), 173-186.

Glick, P., \& Fiske, S. T. (1996). The ambivalent sexism inventory: Differentiating hostile and benevolent sexism. Journal of Personality and Social Psychology, 70(3), 491-512.

Glick, P., \& Fiske, S. T. (1997). Hostile and benevolent sexism: Measuring ambivalent sexist attitudes toward women. Psychology of Women Quarterly, 21(1), 119-135.

Glick, P., Fiske, S. T., Mladinic, A., Saiz, J. L., Abrams, D., Masser, B., ... López, W. L. (2000). Beyond prejudice as simple antipathy: Hostile and benevolent sexism across cultures. Journal of Personality and Social Psychology, 79(5), 763-775.

Glick, P., Sakalli-Ugurlu, N., Ferreira, M. C., \& Souza, M. A. de (2002). Ambivalent sexism and attitudes toward wife abuse in Turkey and Brazil. Psychology of Women Quarterly, 26(4), 292-297.

Green, R. J., Ashmore, R. D., \& Manzi, R. Jr. (2005). The structure of gender type perception: Testing the elaboration, encapsulation, and evaluation framework. Social Cognition, 23(5), 429-464. 
Hofstede, G., Hofstede, G. J., \& Minkov, M. (2010). Cultures and organizations: Software of the mind: Intercultural cooperation and its importance for survival. New York: McGraw-Hill.

Hofstede, G., \& Minkov, M. (2013). Values survey module 2013 manual. Retrieved from https://geerthofstede.com/wp-content/uploads/2016/07/Manual-VSM-2013.pdf [Accessed 2020, December 15].

Johansson, W. (1981). The etymology of the word faggot. Gay Books Bulletin, 6, 16-18.

Jones, M. L. (2007). Hofstede - Culturally Questionable?, Oxford Business \& Economics Conference, Oxford University, UK. Retrieved from https://ro.uow.edu.au/cgi/viewcontent.cgi?article=1389\&context $=$ commpapers [Accessed 2020, December 15].

Kite, M. E., Deaux, K., \& Haines, E. L. (2008). Gender stereotypes. In F. L. Denmark \& Michele A. Paludi (Eds.), Psychology of women: A handbook of issues and theories (pp. 205-236). Westport: Praeger.

Kövecses, Z. (2000). Metaphor and emotion: Language, culture, and body in human feeling. Cambridge: Cambridge University Press.

Kövecses, Z., \& Radden, G. (1998). Metonymy: Developing a cognitive linguistic view. Cognitive Linguistics, 9(1), 37-78.

Lakoff, G., \& Johnson, M. (1980). Metaphors we live by. Chicago: University of Chicago Press.

Lakoff, G., \& Turner, M. (1989). More than cool reason: A field guide to poetic metaphor. Chicago: University of Chicago Press.

LamaPoll. Retrieved from https://www.lamapoll.de/.

López-Sáez, M., \& Lisbona, A. (2009). Descriptive and prescriptive features of gender stereotyping: Relationships among its components. Revista De Psicología Social, 24(3), 363-379.

Lovejoy, A. O. (1936). The Great Chain of Being: A study of the history of an idea. Cambridge: Harvard University Press.

Milhausen, R. R., \& Herold, E. S. (2001). Reconceptualizing the sexual double standard. Journal of Psychology \& Human Sexuality, 13(2), 63-83.

Monto, M. A., \& Supinski, J. (2014). Discomfort with homosexuality: A new measure captures differences in attitudes toward gay men and lesbians. Journal of Homosexuality, 61(6), 899-916.

Neuland, E. (2008). Jugendsprache: Eine Einführung. Tübingen: Francke.

Oxford English Dictionary. Retrieved from http://www.oed.com/.

Pragglejaz Group (2007). MIP: A method for identifying metaphorically used words in discourse. Metaphor and Symbol, 22(1), 1-39.

Prentice, D. A., \& Carranza, E. (2002). What women and men should be, shouldn't be, are allowed to be, and don't have to be: The contents of prescriptive gender stereotypes. Psychology of Women Quarterly, 26(4), 269-281.

Pustka, E. (2015). Expressivität: Eine kognitive Theorie angewandt auf romanische Quantitätsausdrücke. Berlin: Erich Schmidt.

Ramos, M., Barreto, M., Ellemers, N., Moya, M., \& Ferreira, L. (2018). What hostile and benevolent sexism communicate about men's and women's warmth and competence. Group Processes \& Intergroup Relations, 21(1), 159-177. 
Reiss, I. L. (1967). The social context of premarital sexual permissiveness. New York: Holt, Rinehart and Winston.

Rodríguez González, F. (2002). El lenguaje de los jóvenes. Barcelona: Ariel.

Rudman, L. A., \& Glick, P. (2008). The social psychology of gender: How power and intimacy shape gender relations. New York: The Guilford Press.

Schope, R. D., \& Eliason, M. J. (2004). Sissies and tomboys: Gender role behaviors and homophobia. Journal of Gay \& Lesbian Social Services, 16(2), 73-97.

Spence, J. T., \& Buckner, C. E. (2000). Instrumental and expressive traits, trait stereotypes, and sexist attitudes: What do they signify? Psychology of Women Quarterly, 24, 44-62.

Spencer, N. E. (2003). "America's sweetheart" and "Czech-mate": A discursive analysis of the EvertNavratilova rivalry. Journal of Sport \& Social Issues, 27(1), 18-37.

Vonk, R., \& Ashmore, R. D. (2003). Thinking about gender types: Cognitive organization of female and male types. British Journal of Social Psychology, 42, 257-280.

Vonk, R., \& Olde-Monnikhof, M. (1998). Gender subgroups: Intergroup bias within the sexes. European Journal of Social Psychology, 28(1), 37-47.

Williams, J., Satterwhite, R., \& Best, D. (1999). Pancultural gender stereotypes revisited: The five factor model. Sex Roles, 40(7), 513-525.

Yu, N. (2008). Chapter 21: Metaphor from body and culture. In R. W. Gibbs, Jr. (Ed.), The Cambridge handbook of metaphor and thought (pp. 247-261). New York: Cambridge University Press.

Zaikman, Y., \& Marks, M. (2014). Ambivalent sexism and the sexual double standard. Sex Roles, 71(9), 333344.

Since March 2016, Kristina FERNANDES, formerly Dziallas, has been a PhD student at the Department for Romance Studies at the University of Vienna in Austria. Her supervisor is Prof Dr Elissa Pustka. In her dissertation project, Kristina Fernandes analyses gender stereotypes as well as gender metaphors in English, Spanish and French and investigates the role they play in linguistic sexism. Her research interests include gender studies, gender stereotypes, gender discrimination, gender inequality, cognitive semantics, conceptual metaphor and metonymy, as well as Spanish phonology and linguistic variation. She has taught introductory courses in Spanish linguistics as well as seminars on linguistic politeness and impoliteness. 


\section{Appendix}

Data set of the less frequently mentioned expressions for different types of women and men in the brainstorming sessions in London and Madrid (alphabetical order).

\begin{tabular}{|c|c|c|c|}
\hline EWL & EML & EWM & EMM \\
\hline 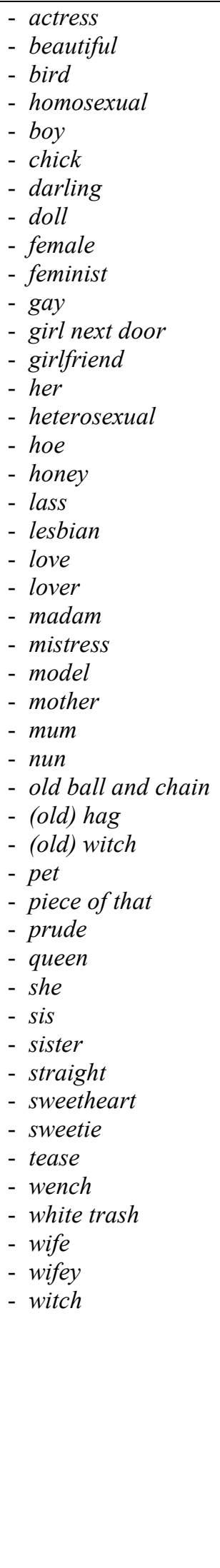 & $\begin{array}{l}\text { - asshole } \\
\text { - babe } \\
\text { - baby } \\
\text { - bastard } \\
\text { - bellend } \\
\text { - homosexual } \\
\text { - bitchboy } \\
\text { - bloke } \\
\text { - boss } \\
\text { - boyfriend } \\
\text { - bro } \\
\text { - brother } \\
\text { - bruv } \\
\text { - bud } \\
\text { - casanova } \\
\text { - cock } \\
\text { - cunt } \\
\text { - darling } \\
\text { - dickhead } \\
\text { - drag (queen) } \\
\text { - father } \\
\text { - fella } \\
\text { - fool } \\
\text { - fuckboy } \\
\text { - fucker } \\
\text { - gay } \\
\text { - gayboy } \\
\text { - geezer } \\
\text { - gentleman } \\
\text { - he } \\
\text { - hench } \\
\text { - heterosexual } \\
\text { - him } \\
\text { - honey } \\
\text { - husband } \\
\text { - idiot } \\
\text { - ladyboy } \\
\text { - legend } \\
\text { - loser } \\
\text { - love } \\
\text { - male } \\
\text { - manslag } \\
\text { - manwhore } \\
\text { - master } \\
\text { - monk } \\
\text { - nonce } \\
\text { - n-word } \\
\text { - prick } \\
\text { - puff } \\
\text { - pussy } \\
\text { - queer } \\
\text { - scrub } \\
\text { - sleaze } \\
\text { - son of a bitch } \\
\text { - straight } \\
\text { fold }\end{array}$ & $\begin{array}{l}\text { - abuela } \\
\text { - amiga } \\
\text { - (mi) amor } \\
\text { - barriobajera } \\
\text { - beba } \\
\text { - bonita } \\
\text { - borracha } \\
\text { - cabrona } \\
\text { - cañón } \\
\text { - chiquet } \\
\text { - chocho } \\
\text { - choni } \\
\text { - chorba } \\
\text { - cielo } \\
\text { - coco } \\
\text { - compañera } \\
\text { - crack } \\
\text { - creída } \\
\text { - cuerpo } \\
\text { - dama } \\
\text { - damisela } \\
\text { - doncella } \\
\text { - ejecutiva } \\
\text { - ella } \\
\text { - esa } \\
\text { - esposa } \\
\text { - facilona } \\
\text { - femenina } \\
\text { - fémina } \\
\text { - figura } \\
\text { - fresca } \\
\text { - gorda } \\
\text { - gordita } \\
\text { - hembra } \\
\text { - hermana } \\
\text { - imbécila } \\
\text { - joven } \\
\text { - jovenata } \\
\text { - jovenzuela } \\
\text { - lerda } \\
\text { - loca } \\
\text { - madamequeñita } \\
\text { - madre } \\
\text { - maja } \\
\text { - marimacho } \\
\text { - marquesa } \\
\text { - moza } \\
\text { - muchacha } \\
\text { - mujer } \\
\text { - mujerona } \\
\text { - mava } \\
\text { - mana }\end{array}$ & 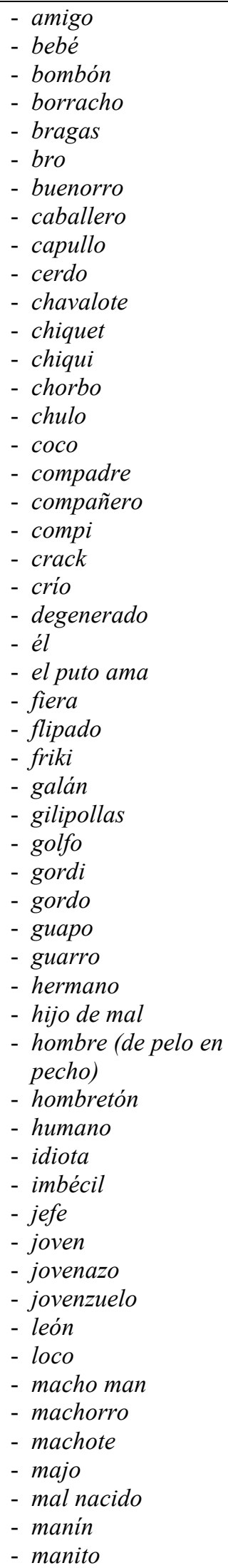 \\
\hline
\end{tabular}


GENDER STUDIES 19(1)/2020

\begin{tabular}{|c|c|c|c|}
\hline . & $\begin{array}{l}\text { - stupid } \\
\text { - sweetheart } \\
\text { - tranny } \\
\text { - trans } \\
\text { - twat } \\
\text { - wanker }\end{array}$ & $\begin{array}{l}\text { - perra } \\
\text { - persona } \\
\text { - pichón } \\
\text { - pituti } \\
\text { - preciosa } \\
\text { - prima } \\
\text { - puta } \\
\text { - santa } \\
\text { - sexo débil } \\
\text { - solterona } \\
\text { - teta } \\
\text { - tía buena } \\
\text { - tiwi } \\
\text { - tronca } \\
\text { - trueno } \\
\text { - verdulera } \\
\text { - víbora } \\
\text { - vieja } \\
\text { - zorra }\end{array}$ & $\begin{array}{l}\text { - marica } \\
\text { - marido } \\
\text { - maromo } \\
\text { - marqués } \\
\text { - masculino } \\
\text { - mozo } \\
\text { - muchacho } \\
\text { - mujeriego } \\
\text { - nano } \\
\text { - nene } \\
\text { - novio } \\
\text { - padre } \\
\text { - pana } \\
\text { - parse } \\
\text { - pavo } \\
\text { - persona } \\
\text { - personaje } \\
\text { - pinche } \\
\text { - pivón } \\
\text { - prim } \\
\text { - primo } \\
\text { - príncipe } \\
\text { - putero } \\
\text { - salido } \\
\text { - señorito } \\
\text { - sexo fuerte } \\
\text { - subnormal } \\
\text { - sujeto } \\
\text { - tete } \\
\text { - tipo } \\
\text { - tiwi } \\
\text { - tronco } \\
\text { - tronki } \\
\text { - varón } \\
\text { - viejo } \\
\text { - wey }\end{array}$ \\
\hline
\end{tabular}

